\title{
Perceptions of Occupational Risk by US Commercial Fishermen
}

\author{
Abstract \\ The dangers associated with commercial fishing are well documented, and fishermen \\ consistently face one of the highest job-related mortality risks of all US occupations. \\ This study explored fishermen's perceptions of these risks in a representative sample of \\ Maine commercial fishing vessel captains. Data were collected on sociodemographic \\ characteristics and risk preferences during at sea boardings of working commercial \\ fishing vessels ( $n=233$ ) along the full extent of the Maine coastline. Trends in perceived \\ risk were explored across the various sociodemographic categories. Fishermen in this \\ study consistently undervalued their true occupational risk, and rated it as average despite \\ consistent evidence to the contrary. Those more likely to downgrade the risk of fishing \\ included state registered vessels and those found to be non-compliant with existing safety \\ regulations. Less educated fishermen and those that come from a fishing family were \\ also more likely to underrate the risks, as were those fishermen that displayed risk-loving \\ tendencies in other facets of their lives such as smokers and those that did not use seat \\ belts. Middle-aged fishermen were also more likely underrate the risk than the youngest \\ and oldest groups, suggesting that overconfidence grows and then wanes over time. The \\ results of this study strongly suggest that the current safety training and awareness \\ programs targeting fishermen are inadequate. Furthermore, widespread voluntary \\ participation in organized safety training is unlikely since the majority of fishermen \\ believed that the risks were not relevant to their own activities.
}

Keywords: fishing safety; risk perception; commercial fishing 


\section{Introduction}

Commercial fishing is consistently ranked as one of the most dangerous occupations in the United States [1]. In a recent report by the Bureau of Labor Statistics [2], the fatality rate for fishermen was over three times higher than the second most dangerous occupation, logging. Northeast fisheries ranked especially dangerous, accounting for one-quarter of the commercial fishing fatalities nationally over the last decade (narrowly surpassed only by the Alaskan region with 26\%) [3-4].

Previous studies of fishermen attitudes towards occupational risk suggest that various social and cultural norms impact what is perceived as dangerous or risky [5-6]. Fishermen typically acquire their occupational skills on the water without any formal job training. Many fishermen come from families with a strong fishing heritage, and workers in this occupation are known for their independence and sense of cultural identity [5-7]. Experiencing and surviving accidents are common stories in commercial fishing, which may serve to reinforce the tendency to trivialize these risks [6]. There is also evidence of a fatalistic attitude among fishermen and sense of risk denial [5-6], as well as an overemphasis on 'common sense' at the expense of formal safety training and equipment acquisition [8]. There may also be an element of self-selection and psychological adaption at play in creating a cohort of risk-loving personalities, and fishermen tend to be more 'adventurous' when compared to workers in other land-based occupations [5-7].

The physical risks faced by fishermen are further complicated by a high degree of financial uncertainty in the occupation. Risk averse fishermen have been shown to earn significantly less than their less risk averse counterparts [9], and there is some disagreement in the literature over whether fishermen as a whole tend to be risk-loving or 
risk averse [10]. However, what is clear is that fishermen are constantly faced with making decisions where the financial gain or loss is highly uncertain, such as the choice

of species to fish, gear type to use, and optimal fishing location [9]. Also, the rate of selfemployment in the fishing industry is among the highest in the US workforce [11]; as independent operators, commercial fishing vessel captains are economically vulnerable to the fluctuating price of their catch as well as the cost of inputs such as bait and fuel. Since much of the fishing activity is seasonal, income levels are generally not stable throughout the year.

This research seeks to explore the underlying risk preferences of a comparatively large sample of fishermen actively engaged in the trade along the Maine coastline. The goal of this project is to improve the understanding of how fishermen perceive and manage the occupational hazards they face, which may be used to better design safety training and risk communication efforts. This work builds upon previous efforts to study risk preferences among commercial fishermen by contributing a larger and more representative sample of active fishermen than has previously been presented in the literature.

\section{Methods}

\subsection{Study Design and Population}

A comprehensive survey of commercial fishermen is challenging because they often work across a broad geographic area, and are not centrally located in a factory or similar work environment that would facilitate a population survey. This is evident in the generally low sample sizes $(n=31-121)$ available from previous studies exploring risk and 
safety in the industry $[6-8,12]$. Although it is possible to construct a list of licensed commercial fishermen and administer a mail survey, these lists would be fishery-specific and limited to the geographic reach of the licensing agencies. Also, a simple licensing list would not be representative of the fishermen actively engaged in the trade. To complicate matters, the probability of a widespread response from this cohort to a mail survey is low.

To overcome these problems, a study was designed to directly solicit information on safety practices and risk attitudes during the boarding of working commercial fishing vessels at sea. The boardings were conducted between 2007 and 2009 in cooperation with the Maine Marine Patrol, and funding for this work was provided by the National Oceanic and Atmospheric Administration and Maine Sea Grant. Commercial fishing vessel captains across the entire stretch of Maine coastline were recruited to participate in this study during their normal at sea operations, and were selected randomly among the vessels operating in the study area on the days the survey was conducted. Due to the feasibility of locating working commercial fishing vessels at sea and project budget considerations, the survey was limited to inshore fisheries and primarily consisted of vessels operating within three miles of the Maine coastline. However, the majority of the US fishing fleet is represented by small-scale vessels similar to those targeted in this study [13], and therefore the results should be more broadly representative of commercial fishermen in the region. 


\subsection{Questionnaire}

All vessels operating within the vicinity of the Marine Patrol vessel during the days the surveys were conducted were approached to complete the survey, and the response rate was $100 \%$. After obtaining consent for participation, the fishing vessel captains were asked the series of questions related to sociodemographic characteristics and attitudes towards risk. Additional data on safety equipment and training was also collected as part of the questionnaire, and these results are presented elsewhere [14]. The survey took approximately 5-10 minutes to complete, and the sampling protocol was approved by the University of Maine's Institutional Review Board for the Protection of Human Subjects.

\subsubsection{Sociodemographic Characteristics}

Sociodemographic data on each of the sampled captains was collected to describe and characterize attitudes towards risk across various sociodemographic categories. These data included the age and level of fishing experience of the sampled captain, as well as educational attainment and family history of fishing.

\subsubsection{Attitudes towards Risk}

The captains were asked a series of questions related to risk, including both personal and occupational risk characteristics. Regarding occupational risk, the captains were asked to compare the danger of their occupation to other occupations more generally. They were also asked to compare their occupational risks to the daily activity of driving a car. 
Question 1: "How dangerous do you think fishing is on a scale of one to ten ( 1 being the least and 10 being the most risky)?”

Question 2: “Do you think you're more likely to die in a fishing or car accident?

Other important occupational risk factors noted on the questionnaire were the captains' ability to swim, whether they were fishing alone at the time of sampling, and if the vessel was in compliance with applicable safety regulations based on a review of the onboard equipment [14]. Finally, fishermen were asked an opened ended question to generally describe the risks they face and their feelings about the danger of fishing as an occupation.

Regarding personal risk factors, the captains were asked additional questions related to smoking and seatbelt use. These variables have been used previously as proxies for job risk preferences [15], and there is evidence to suggest that smokers choose riskier jobs and are more accident prone [16].

\subsection{Statistical Analysis}

The survey data were analyzed using STATA 10.1 (College Station, TX). The data were non-normally distributed and in most cases categorical. Statistically significant comparisons were explored using nonparametric tests, including the Wilcoxon Ranksum and Kruskal-Wallis tests. Categorical data comparisons were made using a standard chisquare test. 
An ordered logit model with robust standard errors was constructed to explore the relationship between the reported risk rankings and the characteristics noted above. Based on the relatively small differences across categories and the large standard errors observed in the risk rankings to be described in the next section, the one to ten risk scale was re-categorized as high-medium-low to better tease out these effects. The primary goal of the risk model in this context is to generate testable hypotheses to be explored by later studies, as opposed to prediction.

More specifically,

Risk $=1$ if the risk rating is $<=2.5$ (bounded below by zero)

Risk $=2$ if the risk rating is between 2.5 and 7.5

Risk $=3$ if the risk rating is $>=7.5$ (bounded above by ten)

The probability of a given risk ranking outcome $i$ across the $K$ categories [e.g. high risk ( $\mathrm{i}=3$ ), medium risk ( $\mathrm{i}=2)$, low risk $(\mathrm{i}=1)$ ] for any individual fishermen $j$ is represented by:

$$
\operatorname{Pr}\left(\mathrm{y}_{\mathrm{j}}=\mathrm{i}\right)=\operatorname{Pr}\left(K_{\mathrm{i}-1}<\mathrm{x}_{\mathrm{j}} \beta+\mathrm{u} \leq K_{\mathrm{i}}\right) \text {, where } \mathrm{i}=1,2,3 \text { and } \mathrm{K}=3 \text {. }
$$

\section{Results}

\subsection{Summary of the Study Population}

A total of 233 questionnaires were completed during the data collection period. The boarded fishing vessels were distributed across the full extent of the Maine coastline, and are geographically representative of Maine coastal waters. The individual boarding locations of each of the sampled captains are noted in Figure 1 and a summary of the collected data are provided in Table 1 . The sampled captains were overwhelmingly white male (only one non-white and one female captain were observed). Most captains were 
raised in a fishing family, and many reported fishing with family members as toddlers. Most fishermen were highly experienced at the trade, with nearly 30 years of fishing on average, and $75 \%$ were full-time fishermen by the age of 21 . The median age of the sampled captains was 45 . Nearly one-third reportedly pursued some level of education beyond high school, although this typically did not include college graduation.

The majority of the inshore vessels sampled were engaged in lobster fishing, which reflects the importance of the lobster industry to Maine. Relatively few shrimp and scallop vessels were present in the targeted areas during the study period, while the urchin and sea cucumber vessels were observed only during the winter months along the Canadian border. There was an even split between federally documented and state registered vessels (federally documented vessels are subject to more stringent safety requirements).

\section{[Insert Table 1 and Figure 1]}

\subsection{Attitudes Towards Risk}

Fishermen generally showed risk-loving tendencies in their daily lives. Approximately $30 \%$ smoked tobacco compared to less than $23 \%$ of men more generally in Maine [17]. Nearly half of all captains reported wearing seatbelts while driving a car, an average that is substantially lower than the national rate of $81 \%$ for US males [18]. Many fishermen reported second jobs in other well known risky occupations, such as logging, trucking, and firefighting. A surprising $12 \%$ of fishermen reported being unable to swim and $17 \%$ of fishermen were observed fishing alone, both of which represent important occupational risk factors. Based on a review of the safety equipment at the 
time of boarding, $42 \%$ of the surveyed vessels were not in compliance with applicable safety regulations [14].

The differences in risk attitudes across the various sociodemographic categories highlight a number of interesting trends, although most of these differences are not statistically significant. This is likely the result of relatively small differences across the categories, coupled with large standard errors among the risk rankings. Although this study collected twice as much data as previous studies, more data are clearly needed to establish statistically significant trends given the present distributions.

Overall, the surveyed captains rated the risk of fishing at the mid-range of 5.5 on a 10 point scale despite consistent evidence of fishing as a high risk occupation. In reality, fishing mortality risks are 60 times higher than other occupations (200 deaths per 100,000 workers in fishing compared to 3.3 per 100,000 workers for all occupations) [2]. Smokers and non-seatbelt wearers downgraded the risk when compared to their nonsmoking and seatbelt wearing counterparts. Also, fishermen that could not swim, were less educated, and came from a family history of fishing also rated their risks lower. Those fishermen sampled in the summer, when fishing risks tend to be lower because of warmer water temperatures, rated the risk lower than fishermen sampled at other times of year. Those captains with crew (not fishing alone) tended to rate the risk lower, as did the captains of vessels that were in compliance with existing safety regulations. Based on the categorical groups of age and experience, there appears to be an increasing effect of age on risk ratings (older fishermen rated the risk as higher), while the impact of experience is non-linear (risk ratings peak with greater experience and then decline again). 
The overwhelming majority (88\%) thought that driving a car was more dangerous than fishing, although in reality fishing fatalities are much more common than automobile-related fatalities. Comparative responses to the automobile-fishing comparisons tended to run counter to the responses ranking occupational risk more generally. In other words, categories of fishermen that rated fishing risks as higher also tended to select driving a car as more dangerous than fishing. However, there was very little variability in the fishermen responses to this question, as the overwhelming majority of fishermen thought that the car was more dangerous.

In response to the open-ended question to generally describe their views towards fishing risks, there was an overwhelming tendency for fishermen to perceive the fishing risks as isolated to those fishermen that were not careful, while rating their own personal activities as low risk. Many reported that the occupational hazards did not apply to small vessels, or that the risk was isolated to certain off-shore fisheries. There was a general failure to recognize the role that accidents, weather, and other elements outside of their control play in fishing risk. This is despite the fact that many fishermen reported having survived a life-threatening accident, or knew someone who had perished on the job. Many fishermen also blamed fisheries regulations and catch limits for declining safety practices.

Table 2 provides the estimated coefficients and robust standard errors from an ordered logit model categorizing the risk rankings as high-medium-low. The relatively low predictive value of the model $\left(\mathrm{R}^{2}=0.08\right)$ is not unexpected in light of the distributional and sample size issues noted earlier. However, the coefficient signs are all in the expected direction. The results provide suggestive evidence to support the 
hypotheses that non-smoking fishermen and those that routinely wear their seatbelts are more likely to rate the fishing risks as higher. This suggests that those workers that are more risk averse in their daily lives are also more attuned to the fishing hazards. More educated fishermen rate these risks as higher, suggesting that education may play a role in more accurately perceived occupational risk. Being from a fishing family makes fishermen more likely to underrate the risks, which could be the result of psychological adaptation and desensitization to the daily hazards. Federally documented vessels, i.e. those subjected to more stringent safety requirements, are more likely to rate the risks as higher, as are those vessels that are in compliance with existing safety regulations. Lobstermen, along with those observed working in the off-season (not summer) rated fishing risks as lower.

After controlling for the other mitigating factors in risk perception, fishermen that rated fishing as more dangerous than driving a car were also significantly more likely to rate the overall risk of fishing higher $(\mathrm{p}<0.05)$. Finally, the impact of age and experience was statistically significant. There was evidence of an inverted-U relationship between perceived risk and age, with the turning point around age 59 (for fishermen with a typical level of experience). Approximately 15\% of the sampled captains were older than 59. Experience was positively and significantly related to perceived risks, and the interaction term between age and experience was also significant.

\section{[Insert Table 2]}




\section{Discussion}

The dangers associated with commercial fishing are well documented, and fishermen consistently face one of the highest job-related mortality risks of all US occupations [1]. In the vast majority of fatal fishing accidents where causes were identified, casualties could have been prevented with the proper safety equipment and training $[1,4,19]$. Recent data in the US attribute one third of all fishing fatalities to falls overboard; more than half of these fishermen were working alone at the time and none were wearing personal flotation devices. Proper use of safety equipment is especially important in the relatively cold Maine waters; fishermen are twice as likely to survive when cold water equipment are used properly [4]. Despite the strength of the evidence highlighting both the risk of the occupation as well as the benefits of proper safety practices, a large percentage of fishermen still choose not to comply with the existing safety regulations [14].

Although previous studies have highlighted a number of important trends in fishermen's attitudes towards occupational risk, none have been as comprehensive in geographic scope and sample size as the current study. The results of this study clearly support previous work suggesting that fishermen as a whole are risk-loving personalities [5-7]. Not surprisingly, many of the captains surveyed in this study worked part-time in other risky occupations, such as logging and firefighting, which supports the hypotheses of self-selection noted previously.

Fishermen in this study consistently undervalued their true occupational risk, rating it as average despite strong evidence to the contrary. The results generally confirmed the existing literature noting 'risk denial' as a major factor [5]. For example, 
most fishermen attributed the occupational risks to those workers that weren't careful, or to workers in other fisheries or locations. Overall, there was a general failure to understand the larger role that accidents play, along with the importance of safety equipment and training in mitigating these risks.

Experiencing and surviving accidents appeared to reinforce the tendency to trivialize these risks, i.e. since it happened to them and they survived, there's no need to worry about it. As one example, a captain surveyed reported that his father had been in two sinking accidents over the past 10 years, but then rated the risk as average. In a separate example, a captain was missing a finger from a fishing-related accident and reported that he would have likely died had there not been a second person on the vessel at the time of the accident, but when asked to rate his occupational risk he declared it was 'not risky.' These examples represented a common theme among the sampled captains in this study and in previous work [8]. Fishermen consistently cited 'common sense' as the primary means for staying safe on the job, and noted that fishing risks were isolated to those fishermen that weren't careful. The use of 'common sense' to avoid dangerous situations was generally viewed as paramount to safety training and equipment.

There were three primary limitations to the current study. First, most of the observations were from small vessels operating within 3-miles of the coastline, and therefore the results reported here can only be reliably extended to small-scale inshore fisheries. However, small vessels represent the vast majority of commercial fishing vessels operating in US waters (>99\%) [13], and these results should therefore be widely applicable. Although fatalities occur at a higher rate for larger vessels, there is evidence to suggest that accident rates are higher for inshore fishing vessels operating in this 
region [20]. Second, since the study was limited to Maine waters based on the scope of the research and funding, it is unclear how these results might transfer to other geographic locations, especially those beyond the Northeast region of the US. However, the results of this study closely align with previous surveys of fishermen attitudes towards safety and risk, and for this reason it is likely that these results are more broadly applicable across the US fishing fleet. Finally, there was a wide variation in the distribution of responses to the risk rankings by fishermen, which was compounded by relatively small differences in the rankings across the various sociodemographic categories. While differences and trends were observed, in many cases they did not reach statistical significance and the predictive power of the risk model was relatively low. Although this work represents the largest study of its kind to identify risk preferences in commercial fishermen, it is clear that a larger sample size is necessary to establish statistically significant associations given the observed distributions.

\subsection{Policy Implications}

The results of this study suggest that there is much room for improvement in the current safety training and awareness programs targeting fishermen. In most cases, safety training is not required to obtain a fishing license. An important exception to this in Maine is the newly instituted lobster apprentice program, which requires all lobstermen seeking a new license to complete marine safety training. However, the apprentice program does not apply to other fisheries or to previously licensed lobstermen. It is therefore not surprising that a recent review noted that the vast majority of fishermen in 
Maine are not certified in basic lifesaving skills such as CPR and FirstAid, and marine safety training is even scarcer among fishermen in Maine [14].

It is clear from the results presented here that fishermen underrate their true occupational risks. From a policy perspective, this suggests that widespread voluntary participation in organized training and safety awareness programs is unlikely since the majority of fishermen believed the reported risks were not relevant to their own activities. For this reason, there is a strong need for safety training mandates similar to the lobster apprentice program that require safety training as a prerequisite to obtaining and renewing fishing licenses.

Safety training and risk communication efforts should be designed with an understanding of fishermen attitudes towards risk. Based on the results of this study, the groups most in need of improved safety awareness and targeted training efforts, i.e. those more likely to underrate their occupational risk, include state registered vessels and captains of vessels that are not compliant with existing safety regulations. Also at risk are less educated fishermen that come from a fishing family, and those fishermen that displayed risk-loving tendencies in other facets of their lives such as smoking and nonseatbelt use. Middle-aged fishermen were also more likely underrate the risk than the youngest and oldest groups, suggesting that overconfidence grows and then wanes over time. 


\section{Acknowledgements}

This study was supported by funding from Maine Sea Grant and the National Oceanic and Atmospheric Administration (R/08-03 NA060AR4170108). The author would like to acknowledge Ann Backus for her contribution to this project, and especially thank her for work related to outreach and communication. The author also recognizes the important role of the many Maine Marine Patrol officers that assisted in the data collection and the commercial fishermen that participated in the study. A special thanks to Eugen Taso, who provided excellent research assistance and aided both in data collection and analysis on this project. 


\section{References}

[1] National Research Council. Fishing Vessel Safety: Blueprint for a National Program. Marine Board Committee on Fishing Vesel Safety. 1991; Washington DC: National Academy Press.

[2] United States Bureau of Labor Statistics, US Department of Labor. National Census of Fatal Occupational Injuries in 2009 (Preliminary Results). 2010; Accessed on August 19, 2010. Available at: http://www.bls.gov/news.release/pdf/cfoi.pdf.

[3] Centers for Disease Control and Prevention. Commercial Fishing Deaths - United States, 2000-2009. Morbidity and Mortality Weekly Report 2010;59(27):842-845.

[4] United States Coast Guard. Analysis of Fishing Vessel Casualties: A Review of Lost Fishing Vessels and Crew Fatalities, 1994-2004. 2006; Washington DC: US Government Printing Office.

[5] Poggie JJ, Pollnac RB, Jones S. Perceptions of vessel safety regulations: a southern New England fishery. Marine Policy 1995;19:411-418.

[6] Pollnac RB, Poggie JJ, Cabral SL. Thresholds of danger: Perceived risk in a New England fishery. Human Organization 1998;57:53-59. 
[7] Poggie JJ, Pollnac RB, Van Dusen C. Intracultural variability in the cognition of danger among southern New England fishers. Marine Resource Economics. 1996;11:2330.

[8] McDonald MA, Kucera KL. Understanding non-industrialized workers’ approaches to safety: How do commercial fishermen "stay safe"? Journal of Safety Research 2007;38:289-297.

[9] Eggert H, Martinsson P. Are commercial fishers risk-lovers? Land Economics 2004;80:550-560.

[10] Smith MD, Wilen JE. Heterogeneous and correlated risk preferences in commercial fishermen: The perfect storm dilemma. Journal of Risk and Uncertainty 2005;31:53-71.

[11] United States Bureau of Labor Statistics, US Department of Labor. Occupational Outlook Handbook (OOH), 2010-2011. 2010; Washington DC: US Government Printing Office.

[12] Kaplan I, Kite-Powell HL. Safety at sea and fisheries management: fishermen's attitudes and the need for co-management. Marine Policy 2000;24:493-498.

[13] Dyer MG. Hazard and risk in the New England fishing fleet. Marine Technology 2000;37:30-49. 
[14] Davis ME. Occupational safety and regulatory compliance in US commercial fishing. Archives of Environmental and Occupational Health, Forthcoming.

[15] Hersch J, Viscusi WK. Cigarette smoking, seatbelt use, and differences in wage-risk tradeoffs. Journal of Human Resources 1990;25:202-227.

[16] Hersch J, Viscusi WK. Smoking and other risky behaviors. Journal of Drug Issues 1998;28:645-661.

[17] Centers for Disease Control and Prevention. State-Specific Prevalence of Cigarette Smoking and Quitting Among Adults - United States, 2004. 2005;54(44):1124-1127.

[18] National Highway Traffic Safety Administration. Traffic Safety Facts Research Note: Seat Belt Use in 2008 - Demographic Results. 2009;DOT HS 811183.

[19] United States Coast Guard. Dying to Fish, Living to Fish: Fishing Vessel Casualty Task Force Report. 1999; Washington DC: US Government Printing Office.

[20] Jin D, Thunberg E. An analysis of fishing vessel accidents in fishing areas off the northeastern United States. Safety Science 2005;43:523-540. 
Figure 1: Map of At-Sea Boarding Locations

[See separately attached jpeg files (both color and grayscale)] 
Table 1: Summary of Risk Characteristics

\begin{tabular}{|c|c|c|c|c|c|}
\hline & Obs & $\begin{array}{l}\text { \% of } \\
\text { sample }\end{array}$ & $\begin{array}{l}\text { Median } \\
\text { Risk Rating }\end{array}$ & $\begin{array}{l}\text { Stan Dev } \\
\text { Risk Rating }\end{array}$ & $\begin{array}{l}\text { \% Reporting Fishing More } \\
\text { Dangerous than Driving }\end{array}$ \\
\hline Total Sample & 233 & $100 \%$ & 5.5 & 2.2 & $12 \%$ \\
\hline \multicolumn{6}{|l|}{ Fishery } \\
\hline Lobster & 180 & $78 \%$ & 5.0 & 22 & $9 \% * * *$ \\
\hline Scallop & 9 & $4 \%$ & 7.0 & 1.5 & $11 \%$ \\
\hline Shrimp & 4 & $2 \%$ & 6.3 & 3.2 & $\mathrm{n} / \mathrm{a}$ \\
\hline Urchin/Sea Cucumber & 37 & $16 \%$ & 6.0 & 2.5 & $24 \%$ \\
\hline \multirow{2}{*}{\multicolumn{6}{|c|}{ Reported smoking }} \\
\hline & & & & & \\
\hline Smoker & 70 & $30 \%$ & 5.3 & 2.3 & $15 \%$ \\
\hline Non-smoker & 163 & $70 \%$ & 5.5 & 2.2 & $10 \%$ \\
\hline \multicolumn{6}{|l|}{ Reported seatbelt use } \\
\hline Wears seatbelt & 111 & $48 \%$ & 6.0 & 2.3 & $10 \%$ \\
\hline Does not wear seatbelt & 111 & $52 \%$ & 5.0 & 2.1 & $13 \%$ \\
\hline \multicolumn{6}{|l|}{ Swim } \\
\hline Able to swim & 194 & $88 \%$ & $5.5^{*}$ & 2.1 & $12 \%$ \\
\hline Not able to swim & 27 & $12 \%$ & 5.0 & 2.8 & $13 \%$ \\
\hline \multicolumn{6}{|l|}{ Number of crew } \\
\hline Fishing alone & 40 & $17 \%$ & 6.0 & 1.7 & $16 \%$ \\
\hline Not fishing alone & 193 & $83 \%$ & 5.0 & 2.3 & $11 \%$ \\
\hline \multirow{2}{*}{\multicolumn{6}{|c|}{ Compliance with safety requlations }} \\
\hline & & & & & \\
\hline Compliant & 131 & $58 \%$ & 5.0 & 2.1 & $12 \%$ \\
\hline Non-compliant & 96 & $42 \%$ & 5.8 & 2.4 & $11 \%$ \\
\hline \multicolumn{6}{|l|}{ Vessel documentation } \\
\hline Federally documented vessel & 106 & $47 \%$ & 5.5 & 2.1 & $9 \%$ \\
\hline State registered vessel & 121 & $53 \%$ & 5.0 & 2.3 & $14 \%$ \\
\hline \multicolumn{6}{|l|}{ Season sampled } \\
\hline Winter & 20 & $9 \%$ & 6.0 & 1.8 & $6 \%$ \\
\hline Spring & 70 & $30 \%$ & 5.8 & 2.2 & $17 \%$ \\
\hline Summer & 89 & $38 \%$ & $5.0^{*}$ & 2.3 & $12 \%$ \\
\hline Fall & 54 & $23 \%$ & 5.5 & 2.2 & $6 \%$ \\
\hline \multicolumn{6}{|l|}{ Postsecondary education } \\
\hline Some college/technical training & \begin{tabular}{|l|}
73 \\
\end{tabular} & $31 \%$ & $6.5^{*}$ & 2.0 & $6 \% *$ \\
\hline No college/technical training & 159 & $69 \%$ & 5.0 & 2.3 & $14 \%$ \\
\hline \multicolumn{6}{|l|}{ Family history of fishing } \\
\hline $\begin{array}{l}\text { Family history of fishing } \\
\text { Family history }\end{array}$ & 193 & $83 \%$ & $5.0 * *$ & 2.3 & $13 \%$ \\
\hline No family history & 40 & $17 \%$ & 7.0 & 2.9 & $5 \%$ \\
\hline \multicolumn{6}{|l|}{ Captain aqe } \\
\hline Age $<36$ years & 57 & $24 \%$ & 5.0 & 2.0 & $20 \%$ \\
\hline Age $36-44$ years & 55 & $24 \%$ & 5.5 & 2.1 & $11 \%$ \\
\hline Age $45-52$ years & 61 & $26 \%$ & 6.0 & 2.0 & $6 \%$ \\
\hline Age $53-85$ years & 60 & $26 \%$ & 6.5 & 2.6 & $11 \%$ \\
\hline \multicolumn{6}{|l|}{ Captain experience } \\
\hline Experience $<17$ years & 57 & $25 \%$ & 5.5 & 2.3 & $16 \%$ \\
\hline Experience $17-26$ years & 56 & $24 \%$ & 5.5 & 2.3 & $15 \%$ \\
\hline Experience $27-35$ years & 61 & $26 \%$ & 6.0 & 2.2 & $7 \%$ \\
\hline Experience $36-70$ years & 59 & $25 \%$ & 5.0 & 2.3 & $9 \%$ \\
\hline
\end{tabular}


Table 2: Results of Ordered Logit Model

\begin{tabular}{|c|c|c|c|}
\hline \multicolumn{4}{|c|}{ Dependent Variable: Risk Ranking High (3) Medium (2) Low (1) } \\
\hline Independent Variables & Description & Coefficient & Robust SE \\
\hline Documentation & $\begin{array}{l}\text { Vessel federally documented (1) or state } \\
\text { registered (0) }\end{array}$ & 0.46 & 0.37 \\
\hline Compliance & $\begin{array}{l}\text { Vessel in compliance with safety } \\
\text { regulations (yes }=1 ; \text { no }=0 \text { ) }\end{array}$ & 0.05 & 0.32 \\
\hline College & $\begin{array}{l}\text { Captain post-secondary education } \\
(\text { yes }=1 ; \text { no }=0 \text { ) }\end{array}$ & 0.57 & 0.36 \\
\hline Family & $\begin{array}{l}\text { Captain from a fishing family (yes=1; } \\
\text { no=0) }\end{array}$ & -0.06 & 0.43 \\
\hline Swim & $\begin{array}{l}\text { Captain able to swim } \\
\text { (yes }=1 ; \text { no=0) }\end{array}$ & 0.86 & 0.58 \\
\hline Seatbelt & $\begin{array}{l}\text { Captain seatbelt use } \\
\text { (yes }=1 ; \text { no }=0 \text { ) }\end{array}$ & 0.19 & 0.31 \\
\hline Age & Age of captain & $-0.17 * *$ & 0.09 \\
\hline $\mathrm{Age}^{2}$ & Age-squared of captain & $0.004^{* * *}$ & 0.002 \\
\hline Experience & Captain number of years fishing & $0.12 *$ & 0.07 \\
\hline Experience $^{2}$ & Captain number of years fishing-squared & 0.003 & 0.002 \\
\hline Age-Experience & Interaction term of age and experience & $-0.01 * *$ & 0.003 \\
\hline Fishing vs. driving & $\begin{array}{l}\text { Captain rated fishing more dangerous } \\
\text { than driving a car (yes }=1 ; \mathrm{no}=0 \text { ) }\end{array}$ & $1.1^{* *}$ & 0.50 \\
\hline Lobster & $\begin{array}{l}\text { Vessel engaged in lobster fishery } \\
\text { (yes }=1 ; \text { no }=0 \text { ) }\end{array}$ & -0.37 & 0.48 \\
\hline Smoker & $\begin{array}{l}\text { Captain smokes } \\
(\text { yes }=1 ; \text { no }=0)\end{array}$ & -0.42 & 0.35 \\
\hline Summer & $\begin{array}{l}\text { Vessel observed fishing in summer } \\
\text { season (yes }=1 ; \text { no }=0 \text { ) }\end{array}$ & -0.47 & 0.37 \\
\hline
\end{tabular}

Note: ${ }^{* * *} \mathrm{p}<0.01 ;{ }^{* *} \mathrm{p}<0.05 ;{ }^{*} \mathrm{p}<0.10$ 